\title{
LANDSAT 9: MISSION STATUS AND PRELAUNCH INSTRUMENT PERFORMANCE CHARACTERIZATION AND CALIBRATION
}

\author{
Brian Markham ${ }^{1}$, Cody Anderson ${ }^{2}$, Julia Barsi $^{3}$, Michael Choate $^{2}$, Eric Donley ${ }^{4}$, Boryana Efremova ${ }^{5}$, \\ Jason Hair ${ }^{1}$, Del Jenstrom ${ }^{1}$, Edward Kaita ${ }^{3}$, Ed Knight ${ }^{4}$, Geir Kvaran ${ }^{4}$, Joel McCorkel ${ }^{1}$, Matthew \\ Montanaro $^{6}$, Eric Morland $^{4}$, Jeffrey Pedelty $^{1}$, Aaron Pearlman ${ }^{5}$, Brian Sauer ${ }^{2}$, James Storey $^{7}$, Brian \\ Wenny. \\ ${ }^{1}$ NASA, Goddard Space Flight Center, Greenbelt, MD 20771, USA \\ ${ }^{2}$ US Geological Survey, Earth Resources Observations and Science Center, Sioux Falls, SD 57198, \\ USA \\ ${ }^{3}$ Science Systems and Applications, Goddard Space Flight Center, Greenbelt, MD 20771, USA \\ ${ }^{4}$ Ball Aerospace, Boulder, CO 80301, USA \\ ${ }^{5}$ GeoThinkTank, Goddard Space Flight Center, Greenbelt, MD 20771, USA \\ ${ }^{6}$ Rochester Institute of Technology, Rochester, NY 14623, USA \\ ${ }^{7}$ Stinger Ghaffarian Technologies, Contractor to US Geological Survey, Earth Resources Observations \\ and Science Center, Sioux Falls, SD 57198, USA
}

\begin{abstract}
Landsat 9 is currently under development as a joint effort between NASA and the United States Geological Survey (USGS). Landsat 9 is essentially a rebuild of Landsat 8 and has the same two sensors, the Operational Land Imager (OLI) and the Thermal Imaging Sensor (TIRS). The OLI-2 on Landsat 9, is being built by Ball Aerospace and has completed its pre-launch characterization and calibration and is scheduled to be delivered in the summer of 2019. The TIRS-2, being built by Goddard Space Flight Center, is currently undergoing testing through Spring 2019 and also scheduled for summer 2019 delivery. Several improvements to the characterization of both instruments have been incorporated into the testing plan, including improved spectral and radiometric characterization. The instruments will then be integrated onto the spacecraft being built by Northrop Grumman Innovation Systems (NGIS). The mission is targeted to launch as early as December 2020 on an Atlas-5.
\end{abstract}

Index Terms - Landsat, characterization, calibration, radiometry, OLI-2, TIRS-2

\section{INTRODUCTION}

Landsat 9 continues the series of Earth imaging satellites that started nearly 50 years ago with Landsat 1 . The shift to push broom instruments that occurred with the Landsat 8 is maintained with Landsat 9, with Landsat 9 being largely a copy of Landsat 8. The instruments on Landsat 9, the second Operational Land Imager (OLI-2), Figure 1 and the second Thermal Imaging Sensor (TIRS-2), Figure 2 have nominally the same characteristics as their Landsat 8 counterparts (Table $1)$.

Table 1. Landsat 9 instrument spectral and spatial characteristics (based on initial integrated instrument data reduction - refinements in process)

\begin{tabular}{|c|c|c|c|c|}
\hline $\begin{array}{c}\text { Band } \\
\#\end{array}$ & Band Name & $\begin{array}{c}\text { Lower } \\
\text { Band } \\
\text { Edge (nm) }\end{array}$ & $\begin{array}{c}\text { Upper } \\
\text { Band } \\
\text { Edge (nm) }\end{array}$ & $\begin{array}{c}\text { Nominal } \\
\text { IFOV } \\
(\mathrm{m})\end{array}$ \\
\hline 1 & $\begin{array}{c}\text { Coastal } \\
\text { Aerosol (CA) }\end{array}$ & 435 & 450 & 30 \\
\hline 2 & Blue & 452 & 512 & 30 \\
\hline 3 & Green & 532 & 589 & 30 \\
\hline 4 & Red & 636 & 672 & 30 \\
\hline 5 & $\begin{array}{c}\text { Near Infrared } \\
\text { (NIR) }\end{array}$ & 850 & 879 & 30 \\
\hline 6 & $\begin{array}{c}\text { Short Wave } \\
\text { Infrared-1 } \\
\text { (SWIR-1) }\end{array}$ & 1565 & 1651 & 30 \\
\hline 7 & $\begin{array}{c}\text { Short Wave } \\
\text { Infrared-2 } \\
\text { (SWIR-2) }\end{array}$ & 2105 & 2294 & 30 \\
\hline 8 & $\begin{array}{c}\text { Panchromatic } \\
\text { (Pan) }\end{array}$ & 503 & 675 & 15 \\
\hline 9 & Cirrus & 1363 & 1384 & 30 \\
\hline 10 & Thermal-1 & 10450 & 11200 & 100 \\
\hline 11 & Thermal-2 & 11600 & 12500 & 100 \\
\hline
\end{tabular}




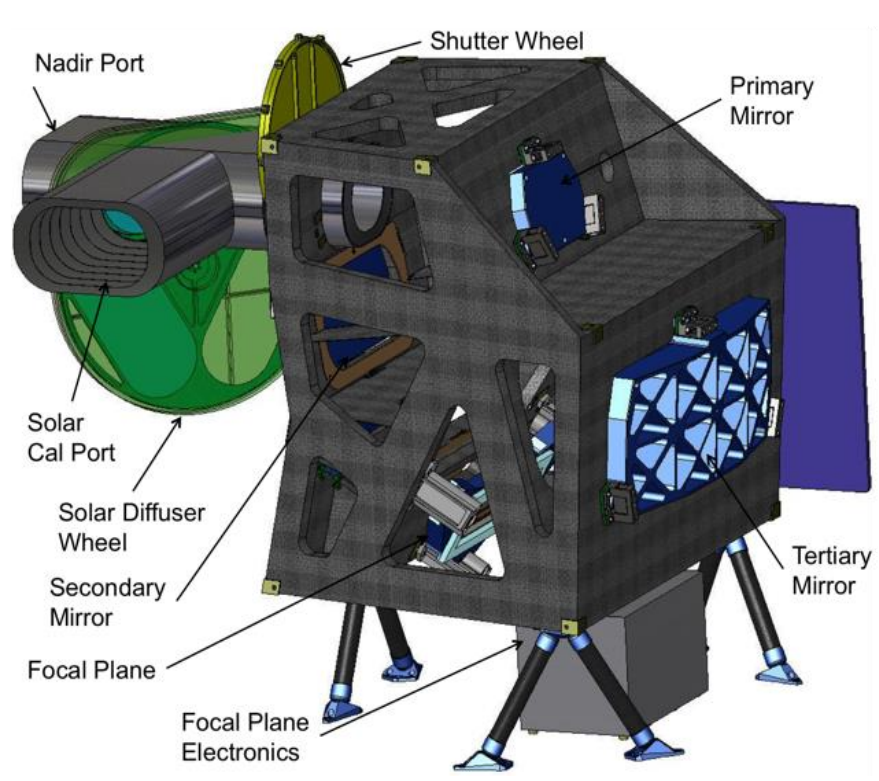

Figure 1. OLI-2 (Ball Aerospace Drawing)

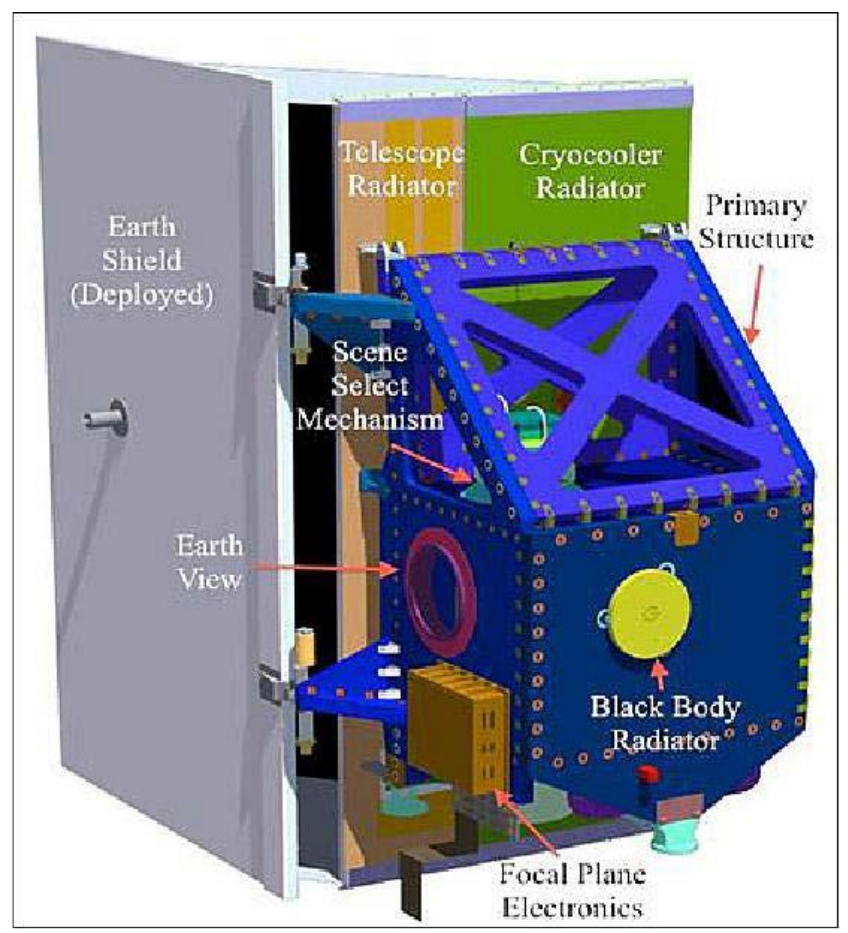

Figure 2. TIRS-2 (NASA/GSFC Drawing)

\section{MISSION STATUS}

Landsat 9 mission development is managed by the NASA Goddard Space Flight Center. Landsat 9 passed its Critical Design Review in the Spring of 2018, and will be beginning integrated mission testing in the Fall of 2019.

\subsection{Operational Land Imager 2}

As of this writing the OLI-2 instrument has completed both sets of performance testing while under thermal vacuum conditions, i.e., the SPAtial Test Set (SPATS), conducted during August to September 2018 and the CAlibration Test Set (CATS), conducted during November and December 2018. SPATS included edge response testing, (akin to MTF), bright target recovery, ghosting and line of sight measurements. CATS testing included spectral response using the Goddard Laser for Absolute Measurement of Radiance (GLAMR), new for OLI-2 [1], as well as radiometric calibration using a traditional broad band integrating sphere source. As of this writing the OLI-2 has completed electromagnetic and vibration testing and thermal vacuum testing is underway.

\subsection{Thermal Infrared Sensor 2}

Similarly, the TIRS-2 instrument has been fully integrated and has completed the first of two thermal vacuum test sequences (TVAC-1), which included performance testing as well as thermal cycling. The instrument has also undergone acoustics, vibration and electromagnetic testing, and is preparing for TVAC-2 testing. Prior to being fully integrated, a limited set of characterization testing, including stray light testing, was performed in the TIRS-2 Imaging Performance and Cryoshell Evaluation (TIPCE)[2]. This configuration, with the Scene Select Mechanism (SSM) and entrance aperture baffles, replaced by the Front End Baffle Simulator (FEBS), allowed the TIRS-2 telescope to get closer to the calibration system and thereby perform testing across a wider range of angles than would be possible with the fully integrated instrument. TIPCE testing verified the improved stray light control implemented in TIRS-2. In addition to scattered light testing, preliminary spectral and spatial response testing were performed.

\subsection{Spacecraft}

The spacecraft is under integration at Northrop Grumman Innovation Systems (NGIS) in Gilbert, AZ. It is based on NGIS's LEOStar-3 platform and leverages many of the Landsat 8 spacecraft design features. Instrument integration onto the spacecraft is currently scheduled for the Fall of 2019.

\subsection{Ground System}

The ground system in under development by the USGS Earth Resources Observation and Science (EROS) Center. The new multi-mission operations center that will operate both Landsats 8 and 9 will be located at the NASA Goddard Space Flight Center and the Data Processing and Archive System will be located at USGSEROS facility. The command/ telemetry and mission data will be handled by the Ground Network Element with facilities around the world. 


\subsection{Launch Vehicle}

Like Landsat 8, the launch vehicle will be a United Launch Alliance Atlas V 401 and will be launched from Vandenberg Air Force Base.

\subsection{Schedule}

The Landsat 9 project is working toward a launch readiness date of December 2020. This will be followed by a 3-month commissioning phase before transitioning to operations, at which point USGS will assume ownership of the mission.

\section{INSTRUMENT PERFORMANCE}

\subsection{OLI-2}

OLI-2 has completed all of its performance testing, though data analysis is still ongoing for the spectral and radiometric characterizations.

\subsubsection{Spatial Characterization}

Spatial testing was performed in a thermal vacuum chamber during July and August 2018. Requirements were

\section{Edge Response Slope}

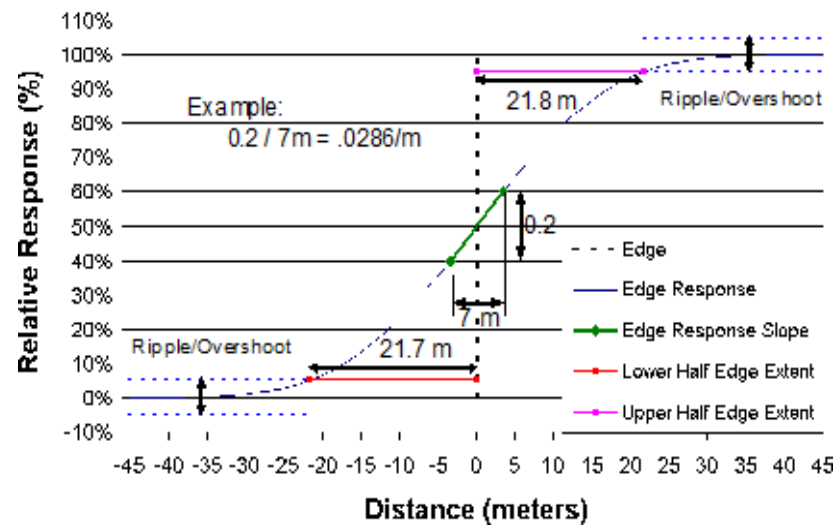

Figure 3. Edge response requirements

specified in terms of edge response slopes and edge extents (Figure 3). The minimum edge slope responses of $0.027 / \mathrm{m}$ for the multispectral bands and $0.054 / \mathrm{m}$ for the pan band were all met in both the along track and across track directions with margins of 15 to $20 \%$ (9\% in pan) in the cross-track direction and half that value in the along-track direction. Along-track direction values are lower due to the effect of the movement during the integration time of the detectors. The edge extent requirements were similarly met, with larger margins in the multispectral bands and the cross-track direction.

\subsubsection{Degree of Linear Polarization}

The degree of linear polarization sensitivity was characterized using a linear polarizer in front of the large aperture integrating sphere. Locations near the center of the focal plane and at the two extreme edges were tested. Performance was similar to the Landsat $8 \mathrm{OLI}$, with the highest sensitivity at about $1 \%$ (versus a requirement of $<5 \%$ ) near the edge of the field of view in the shortest wavelength (coastal aerosol) band. More typically the sensitivity is a few tenths of percent.

\subsubsection{Spectral Characterization}

As discussed in detail in [1], the spectral testing of OLI-2 used tunable laser sources and provided an unprecedented level of detail in the spectral response, measuring all detectors in band and much of the out of band region as well with sufficient signal to noise. For OLI spectral response was only measured in-band at the instrument level (Figure 4)

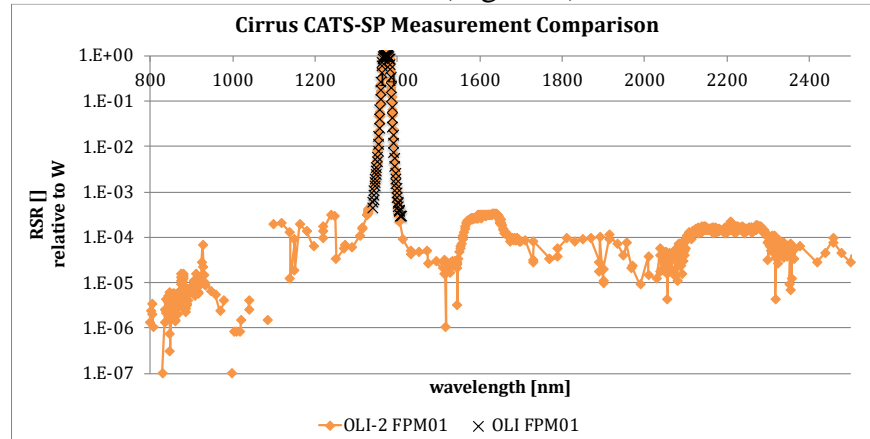

Figure 4. Comparison of instrument level (Calibration Test Set - Spectral [CATS-SP]) RSR measurements for a cirrus band focal plane module (FPM) on OLI (Landsat 8) versus OLI-2 (Landsat 9), showing out-of-band coverage on OLI-2.

\subsubsection{Radiometric Characterization}

Radiometric characterization, i.e., linearity, SNR and relative and absolute radiometric calibration, analyses are ongoing. Initial SNR results as compared to L8 OLI are below (Table 2). The improvement in SNR for OLI-2 is largely due to the retention of all 14 bits, versus truncation to 12 bits (by the spacecraft) for OLI.

Table 2: OLI instrument median SNR values at specified typical radiance values ( $\mathrm{L}_{\text {typical }}$ )

\begin{tabular}{|c|c|c|c|}
\hline Band & $\begin{array}{c}\mathrm{L}_{\text {typical }} \\
\left(\mathrm{W} / \mathrm{m}^{2} \mathrm{sr} \mu \mathrm{m}\right)\end{array}$ & $\begin{array}{c}\text { L8 OLI SNR } \\
(12 \mathrm{bit})\end{array}$ & $\begin{array}{c}\text { L9 OLI-2 SNR } \\
(14 \mathrm{bit})\end{array}$ \\
\hline 1 & 40 & 232 & 263 \\
\hline 2 & 40 & 355 & 442 \\
\hline 3 & 30 & 296 & 366 \\
\hline 4 & 22 & 222 & 268 \\
\hline 5 & 14 & 199 & 249 \\
\hline 6 & 4 & 261 & 314 \\
\hline 7 & 1.7 & 326 & 367 \\
\hline 8 & 23 & 145 & 162 \\
\hline 9 & 6 & 162 & 173 \\
\hline
\end{tabular}

\subsection{TIRS-2}


As indicated above, the TIRS-2 instrument has completed its first fully integrated instrument thermal vacuum testing, where spatial, spectral and radiometric testing was performed. Selected tests were performed at a lower integration level as a precursor for the run for the record. Some of these lower level tests cannot be performed as well at the fully integrated level, particularly the larger angle stray light tests (see below).

\subsubsection{Spatial Characterization}

Similar edge response slope testing was performed as for OLI2 as part of the TIPCE campaign. These initial results indicated performance consistent with the Landsat 8 TIRS, with cross track edge slope values in the 0.0057 to $0.0060 / \mathrm{m}$ and edge extents of 200-230 m [3,4]. Updated results will be presented as available after the fully integrated instrument level testing is completed.

Stray light testing during the TIPCE campaigns confirmed that TIRS-2 will have about an order of magnitude reduction in stray light as compared to TIRS. The problematic stray light at about $13^{\circ}$ off axis in TIRS at about $0.4 \%$ magnitude is reduced to about $0.03 \%$ in TIRS-2[2].

\subsubsection{Spectral Characterization}

Final spectral response derivations will be based on the testing during the TVAC campaigns. Preliminary results (Figure 5) indicate performance similar to TIRS and confirm that the integrated instrument level results are more accurate than the predictions based on the component level measurements [5].

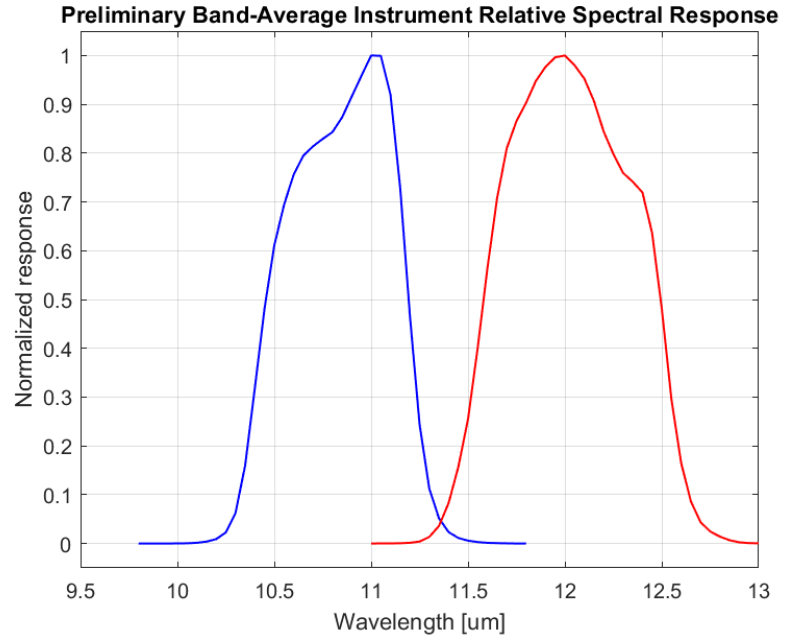

Figure 5. TIRS-2 preliminary relative spectral responses [5]

\subsubsection{Radiometric Characterization}

Radiometric characterization, i.e., linearity, NEdT and relative and absolute radiometric calibration, analyses have been performed. Initial noise analyses indicate performance similar to L8 TIRS (Table 3).

Table 3: Noise Equivalent Delta Temperatures (NEdT) for TIRS instruments bands at indicated temperatures $(\mathrm{K})$

\begin{tabular}{|c|c|c|c|c|}
\hline Instrument & Band & $270 \mathrm{~K}$ & $300 \mathrm{~K}$ & $320 \mathrm{~K}$ \\
\hline \multirow{2}{*}{ L8 TIRS } & 10 & 0.06 & 0.05 & 0.05 \\
\cline { 2 - 5 } & 11 & 0.06 & 0.05 & 0.05 \\
\hline \multirow{2}{*}{ L9 TIRS-2 } & 10 & 0.05 & 0.05 & 0.05 \\
\cline { 2 - 5 } & 11 & 0.08 & 0.07 & 0.06 \\
\hline
\end{tabular}

\section{ACKNOWLEDGEMENTS}

The Landsat 9 project consists of a large team extending across two agencies: NASA and USGS and many contractors. The NASA project manager is Del Jenstrom; the USGS project manager is Brian Sauer; the NASA TIRS-2 instrument manager is Jason Hair; the OLI-2 NASA instrument manager is Param Nair and the Ball Aerospace OLI-2 program is Leanne Presley. The NASA observatory manager is Vicki Dulski. The USGS ground system manager is Steve Zahn.

\section{REFERENCES}

[1] J. McCorkel, B. McAndrew, J. Barsi, B. Zukowski, T. Shuman, M. Rodriguez, A. Sushkov, J. Pharr, B. Markham, “ First results from laser-based characterization of the Landsat 9 Operational Land Imager," Proc. IGARSS 2019 (this issue), 2019.

[2] M. Montanaro, J. McCorkel, J. Tveekrem, J. Stauder, A. Lunsford, E. Mentzell, J. Hair, D. Reuter. Landsat 9 Thermal Infrared Sensor 2 preliminary stray light assessment, Proc. IGARSS 2018, pp 8853-8856, 2018.

[3] J. McCorkel, M. Montanaro, B. Efremova, A. Pearlman, B. Wenny, A. Lunsford, A. Simon, J. Hair and D. Reuter. Landsat 9 Thermal Infrared Sensor 2 characterization plan overview. Proc. IGARSS 2018, pp 8845-8848, 2018.

[4] B. Wenny, D. Helder, J. Hong, L. Leigh, K. Thome, and D. Reuter. Pre and post launch spatial quality of the Landsat 8 Thermal Infrared Sensor, Remote Sensing, 7, pp. 1962-1980, 2015.

[5] B. Efremova, A. Pearlman, J. McCorkel, M. Montanaro, M. Hickey, A. Lunsford, and D. Reuter. Landsat 9 Thermal Infrared Sensor 2 subsystem level spectral test results. Proc. IGARSS 2018, pp. 8849-8852, 2018. 